\title{
Thermal hydraulic performance analysis of rectangular duct having single step rib using CFD as a tool
}

\author{
Suresh Choudhary, Chandan Kumar*, Brij Mohan Sharma \\ Department of Mechanical Engineering, Swami Keshvanand Institute of Technology, Management \& \\ Gramothan, Jaipur-302017 (INDIA) \\ Email: chandanpink1988@gmail.com* \\ Received 12.01.2021, received in revised form 10.05.2021, accepted 11.05.2021
}

\begin{abstract}
The aim of the study is to investigate the effect of single step rib on the thermal hydraulic performance of rectangular duct solar air heater. In present study single step rib has been used to investigate the thermal hydraulic performance by varying various input parameters such as pitch of rib, angle of attack, and Reynolds number using CFD as a tool. However, CFD results have also been validated with experimental work. A rectangular duct has been designed as per ASHARE standards and experiments are performed for smooth plate and then validated with CFD results. The ratio of Nusselt number for artificially roughened plate to the Nusselt number for smooth plate is also calculated in present study. The maximum ratio is achieved at $R e=15000$, for pitch $=30$ $\mathrm{mm}$ and $\mathrm{AOA}=15^{\circ}$, which is 3.54. However, the thermal hydraulic performance parameter was reported to be maximum, corresponding to $\mathrm{Re}=$ $15000, \mathrm{p}=30 \mathrm{~mm}$ and $\mathrm{AOA}=15^{\circ}$, which is 2.91 .
\end{abstract}

Keywords- CFD, Step Rib, Nusselt number, Reynolds number

\section{INTRODUCTION}

In the recent years, the world is facing energy crisis. Due to increase in the population, shortage of oil and coal, higher fuel prices and global economic recession, the demand of energy is on a continuous rise. On the other hand, the per capita consumption of energy is also increasing. This is putting pressure on the conventional sources of energy generation like coal and petroleum which account for around $70 \%$ of total energy production. In order to relieve this pressure, Renewable sources of energy have been visualized as an alternative to the conventional sources of energy to meet the rising energy demands. The global institutions like UNFCCC (United Nations Framework Convention on Climate Change) and UNEP (United Nations Environment Program) are continuously urging the nations to switchover towards renewable sources of energy. Government of India has set an ambitious target of Renewable energy generation whereby it has promised to produce $175 \mathrm{GW}$ of energy through renewable sources of energy by $2022[1,2]$.

Solar air heater is a device which is used to increase the temperature of the incoming air with the help of heat that it absorbs from solar radiation. Solar air heater is less costly, easy to fabricate simple in design, requires very less maintenance and is ecofriendly. As a result, it finds applications in drying of agricultural commodities, seasoning of timber, heating of commercial and domestic buildings, etc. [3]. However, its fundamental weakness is low rate of heat transfer between the air and the absorber plate.

\subsection{Methods to improve the thermal performance of a flat plate solar air heater}

The thermal performance of a solar air heater can be improved by incorporating one or more of the following methods:

- By increasing convective heat transfer coefficient between absorber plate and air.

- By increasing the solar radiation incident on the absorber plate.

- By reducing various losses of heat from the absorber plate

- By augmenting the heat transfer surface area by providing artificial roughness on the absorber plate.

Researchers have proposed diverse approaches to improve thermal performance of $\mathrm{SAH}$ by augmenting the surface area and to increase the convective heat transfer coefficient by breaking up the viscous sub layer [4]:

- Use of fins

- Use of baffles (Thin elements of greater height)

- Use of ribs (Small height projections)

- Use of artificial roughness etc.

Yadav and Bhagoria [3] numerically investigated the performance of a rectangular duct roughened with transverse square sectioned ribs. The best performance was observed (for $\mathrm{p} / \mathrm{e}=10.71$ and $\mathrm{e} / \mathrm{D}$ $=0.042$ ) at $\operatorname{Re}=12000$. Thakur et al. [5] conducted 2D CFD analysis of a solar air heater having absorber plate artificially roughened with novel hyperbolic ribs. The study reported that the hyperbolic ribs perform better than, rectangular, semicircular and triangular ribs when Reynolds number is below 10000. Singh and Singh [6] conducted 3D CFD simulation study on a solar air heater. The absorber plate was provided with saw tooth ribs. RNG k-e model was preferred as 
turbulence model. The study revealed maximum increase in Nusselt number and friction factor as 2.18 times and 2.34 times respectively over smooth duct at Reynolds number 15000 and relative roughness pitch of 16. Singh et al. [7] carried out 3D CFD investigation of and artificially roughened solar heater using RNG k-e model. Four different roughness geometries viz. Non uniform saw tooth rib, square rib, circular rib and trapezoidal ribs were tested. The Reynolds number was changed from 3000 to 15000 . The Nusselt number was reported to be more for non-uniform cross section saw tooth ribs than square, circular and triangular ribs of uniform cross section for Reynolds number values more than 7000 . Trapezoidal ribs reported a higher Nusselt number followed by square ribs and circular ribs within the range of parameters investigated. Singh et al. [8] experimentally investigated the performance of a solar air heater roughened with ' $\mathrm{V}$ down ribs with gaps'. Experimentation was done for five different values relative pitch of roughness viz. 04, 06, 08, 10, 12 and single relative height of roughness equal to 0.043 , within Reynolds number range of 3000-15000. The angle of attack was kept at $60^{\circ}$. The width of gap equal to height of rib gave best results. The best thermal and hydraulic performance was achieved at relative pitch of roughness equal to 8 . The research revealed that ' $V$ down ribs with gap' performs better than transverse, $\mathrm{V}$ shape, discrete $\mathrm{W}$ shape and inclined ribs with gap in terms of Thermo-hydraulic performance. Pandey et al.[9] conducted an experimental study of a rectangular duct roughened with multiple arc shaped ribs with gaps. The experiments were repeated for four different values of relative pitch of roughness $(\mathrm{p} / \mathrm{e}=4-16)$, four different values of angle of attack $\left(30^{\circ}-75^{\circ}\right)$, and four different values of relative height of roughness $(\mathrm{e} / \mathrm{D}=0.016-0.044)$ within a Reynolds number range from 2100 to 21000. The maximum increase in Nusselt number was observed to be 5.85 times and that in friction factor was found to be 4.96 times over smooth duct. After reviewing various published research work on artificial roughness, it is found that there is very less research available in Reynolds number ranged from 5000 to 25000 , so in present study rectangular stepped rib is selected as AR design for different range of $\mathrm{Re}$. In present study $3 \mathrm{D}$ CFD simulation has been carried for solar air heater that has absorber plate roughened with single step rib.

\subsection{Grid independency test}

The test is performed to make the results independent of the number of grids. For this we start with a coarse mesh and measure some of the performance parameter such as Nusselt number in case of a solar air heater [3]. Then mesh is made successively finer and every time the performance parameter is measured. The number of elements for which there is less than $1 \%$ change in the response parameter value is selected for rest of the study. The GIT results are presented in table 1, for different mesh sizes:

Table-1 Grid Independency Test

\begin{tabular}{|c|c|c|c|}
\hline $\begin{array}{c}\text { Mesh Size } \\
\text { (mm) }\end{array}$ & $\begin{array}{c}\text { Reynolds } \\
\text { number }\end{array}$ & Nu (CFD) & $\begin{array}{c}\text { Nu } \\
\text { (D-B correlation) }\end{array}$ \\
\hline $\mathbf{1 . 5}$ & 15000 & 48.38 & 44.80 \\
\hline $\mathbf{2}$ & 15000 & 49.95 & 44.80 \\
\hline $\mathbf{2 . 5}$ & 15000 & 45.29 & 44.80 \\
\hline $\mathbf{3}$ & 15000 & 44.23 & 44.80 \\
\hline $\mathbf{3 . 5}$ & 15000 & 35.39 & 44.80 \\
\hline $\mathbf{4}$ & 15000 & 35.96 & 44.80 \\
\hline $\mathbf{4 . 5}$ & 15000 & 38.40 & 44.80 \\
\hline $\mathbf{5}$ & 15000 & 40.61 & 44.80 \\
\hline
\end{tabular}

Table 1 indicates that, the grid size $3 \mathrm{~mm}$ is best suitable for this CFD based simulation study. However, $2.5 \mathrm{~mm}$ grid size is also suitable but it only increases computational time of study not the quality of results.

\section{EXPERIMENTAL SETUP}

The photographic view of the experimental setup and schematic diagram of air duct is shown in Figures 1 and 2 respectively. The duct is fabricated as per ASHRAE standards and has dimensions 1600 $\mathrm{mm}$ X $300 \mathrm{~mm}$ X $20 \mathrm{~mm}$. However, the test section is $1000 \mathrm{~mm}$ in length and entry and exit sections are $350 \mathrm{~mm}$ and $250 \mathrm{~mm}$ long respectively. The main components of experimental setup are solar air heater duct, solar simulator consisting of halogen lamps and measuring instruments.

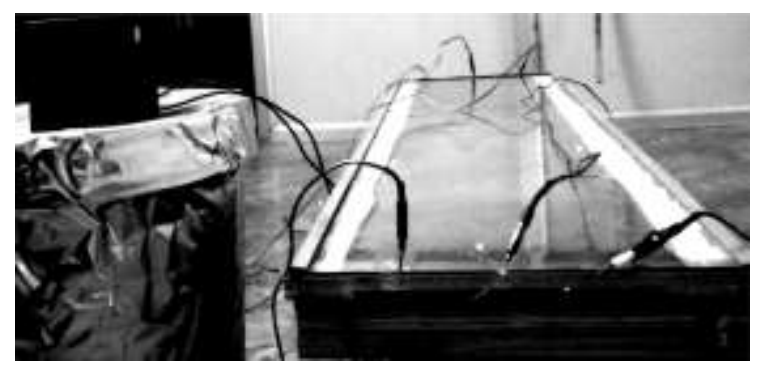

Fig. 1 Air duct experimental setup

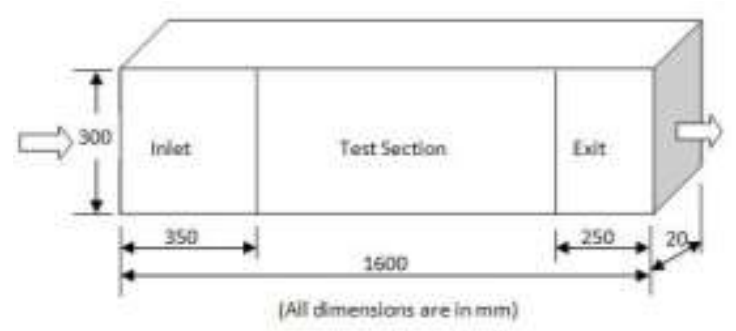

Fig. 2 Schematic diagram of air duct

\subsection{Solar simulator}

Single fluid heat exchangers require input heat to transfer the heat from metal surface which is called "absorber plate" to fluid medium. This task for 
laboratory investigation is completed by using solar simulator device, which is bunch of high voltage halogen lamps. The total heat flux maintained by this device is set around $1000 \mathrm{~W} / \mathrm{m}^{2}$.

\subsection{Solar air heater}

The solar air heater has been constructed in such a way that it can be easily dismantled and its components like glass cover, absorber plate and back plate of duct can be reassembled to change the collector flow configuration. In present study, rectangular air duct with smooth plate has been fabricated. The experiments have been performed only on smooth duct to validate the CFD results

\subsection{Experimental Procedure}

Once experimental setup is fabricated, experimentation should be planned very carefully. The Steps followed for experimental procedure are following:

- Proper air flow arrangement is required to vary air flow conditions. In present work Reynolds number has been varied from 5000 to 25000 .

- Proper insulation is required to reduce heat losses from the setup, for this proper insulation has been provided using glass wool.

- Thermo-couples have been installed at entry and exit sections of rectangular air duct for temperature measurement. Four thermocouples have been installed at inlet and exit section each. Measured temperatures are then averaged for final calculation of heat transfer rate. Four thermo-couples were provided on absorber plate for measurement of temperature.

- Due to lack of pressure measuring devices, no pressure is measured in present setup, only UTube manometer is installed at inlet and exit section. This device shows no pressure drop for these sections.

- Solar simulator is made with 08 halogen lamps of $200 \mathrm{~W}$ capacities each.

\subsection{Experiment validation}

The experimental validation is performed for smooth duct at three different Reynolds number values, which are presented in table 2 .

Table 2 Experimental validations Analysis

\begin{tabular}{|c|c|c|c|}
\hline $\begin{array}{c}\text { Reynolds } \\
\text { number }\end{array}$ & Nu (Ex) & Nu (CFD) & $\begin{array}{c}\text { Nu (D-B } \\
\text { correlation) }\end{array}$ \\
\hline $\mathbf{5 0 0 0}$ & 15.91 & 17.81 & 18.60 \\
\hline $\mathbf{1 5 0 0 0}$ & 38.46 & 44.65 & 44.80 \\
\hline $\mathbf{2 5 0 0 0}$ & 57.18 & 68.47 & 67.41 \\
\hline
\end{tabular}

The results are presented in figure 3 , for better analysis. Figure 3, indicates that CFD results for this research work are in good agreement with experimental and D-B correlation results.

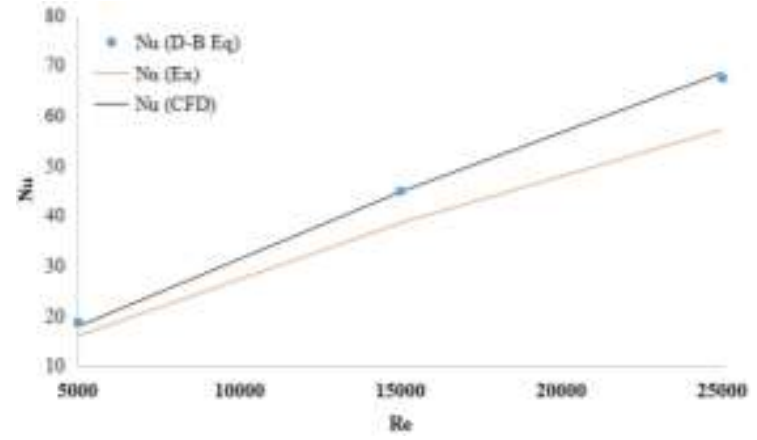

Fig. 3 Experimental Validations for Rectangular Duct

Artificial Roughness making for CFD simulation In present study thermal hydraulic performance investigation has been planned with single step rib as artificial roughness. The roughness geometry has been created using CFD fluent.

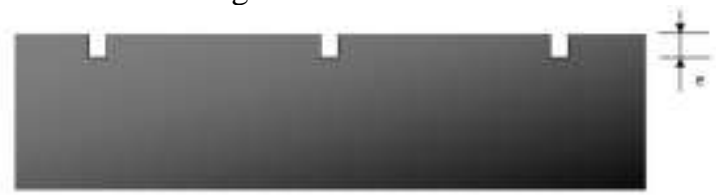

Fig. 4 Single Step Rib $(\mathrm{e}=1 \mathrm{~mm})$

After the selection of geometry for artificial roughness, Input parameters were finalized for CFD simulations. Table 3 represents the input parameters:

Table 3 Input parameters for present study

\begin{tabular}{|l|l|l|}
\hline $\mathbf{1}$ & Reynolds Number $(\mathrm{Re})$ & $5000,15000,25000$ \\
\hline $\mathbf{2}$ & Pitch $(\mathrm{p})$ & $20,30,40(\mathrm{~mm})$ \\
\hline $\mathbf{3}$ & Effective height of rib $(\mathrm{e})$ & $1(\mathrm{~mm})$ \\
\hline $\mathbf{4}$ & Type of Rib & Single step rib \\
\hline $\mathbf{5}$ & Angle of Attack $(\alpha)$ & $0^{\circ}, 15^{\circ}, 30^{\circ}$ \\
\hline $\mathbf{6}$ & Heat flux & $1000 \mathrm{~W} / \mathrm{m}^{2}$ \\
\hline
\end{tabular}

\section{RESULTS AND DISCUSSION}

Effect on Nusselt Number: Dimensionless Nusselt number is calculated in present study for all cases of artificial roughness. In this section different roughness geometries are compared with reference to smooth plate. The $\mathrm{Nu}$ number results for single step rib are shown in figure 5 , at different pitch and angle of attack.

As seen in figure 5, it is clearly indicated that by increasing the $\mathrm{Re}$ number, $\mathrm{Nu}$ number also increases. Nu number increment in single step rib is much higher than smooth plate rectangular duct. Table 4 represents the ratio of $\mathrm{Nu}$ number for rough and smooth plates $\left(\mathrm{Nu}_{\mathrm{AR}} / \mathrm{Nu}_{\text {smooth }}\right)$.

Ratio of $\mathrm{Nu}_{\mathrm{AR}} / \mathrm{Nu}_{\text {smooth }}$ is highest for case $\mathrm{p}=30 \mathrm{~mm}$, $\mathrm{AOA}=15^{\circ}$ and $\mathrm{Re}=15000$ which is equal to 3.54 . However, with the introduction of artificial roughness, friction factor also increases. Table 6 represents the ratio of friction factor for rough plate to the smooth plate. 


\section{CONCLUSION}

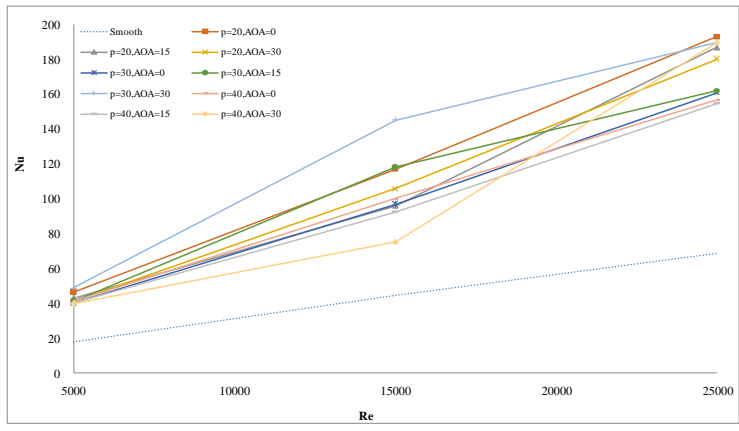

Fig. 5 Comparison of Nu number of Air Stream for Single step rib

The thermo-hydraulic performance of a solar air heater is best described by a parameter known as Thermal Hydraulic Performance Parameter ( $\eta$ ), which is given by:

$$
\eta=\frac{\left(N u_{A R} / N u_{\text {smooth }}\right)}{\left(f f_{A R} / f f_{\text {smooth }}\right)^{1 / 3}}
$$

In present study thermal hydraulic performance parameter has also been calculated and was found to be maximum at $\mathrm{p}=30 \mathrm{~mm}, \mathrm{e}=1 \mathrm{~mm}$ and $\mathrm{AOA}=$ $30^{\circ}$ corresponding to $\operatorname{Re}=15000$, which is 2.91 .
In consequence of a 3-D CFD study of fluid flow and heat transfer characteristics of a rectangular duct roughened with single step rib, the following conclusions can be drawn:

- The relative error for simulated results with D$\mathrm{B}$ correlation is less than $1 \%$ but relative error with experiment is less than $15 \%$. The reason for increasing error in experimental work is various unwanted heat losses that occur in experimental work

- For single step rib, the ratio NuAR/Nusmooth was reported to be maximum at $\mathrm{p}=30 \mathrm{~mm}$ and $\mathrm{AOA}=15^{\circ}$, corresponding to $\operatorname{Re}=15000$, which is 3.54 .

- For single step rib, the ratio ffAR/ffsmooth was reported to be maximum at $\mathrm{p}=20 \mathrm{~mm}$ and $\mathrm{AOA}=0^{\circ}$, corresponding to $\mathrm{Re}=25000$, which is 1.76 .

- The maximum value of thermal hydraulic performance parameter was reported to be 2.95 at $\mathrm{p}=30 \mathrm{~mm}, \mathrm{e}=1 \mathrm{~mm}$ and $\mathrm{AOA}=30^{\circ}$ corresponding to $\operatorname{Re}=15000$, which is 2.91 .

Table 4 Ratio of $\mathbf{N u}_{\mathrm{AR}} / \mathbf{N u}_{\text {smooth }}$ for single height AR for different Reynolds number

\begin{tabular}{|c|c|c|c|c|c|c|c|c|c|}
\hline $\mathbf{R e}$ & $\begin{array}{l}\mathrm{p}=20 \mathrm{~mm}, \\
\text { AOA }=0^{\circ}\end{array}$ & $\begin{array}{l}\text { p=20mm, } \\
\text { AOA }=15^{\circ}\end{array}$ & $\begin{array}{l}\mathrm{p}=20 \mathrm{~mm}, \\
\mathrm{AOA}=30^{\circ}\end{array}$ & $\begin{array}{l}\mathrm{p}=30 \mathrm{~mm}, \\
\mathrm{AOA}=0^{\circ}\end{array}$ & $\begin{array}{l}p=30 \mathrm{~mm}, \\
\mathrm{AOA}=15^{\circ}\end{array}$ & $\begin{array}{l}\mathrm{p}=30 \mathrm{~mm}, \\
\mathrm{AOA}=30^{\circ}\end{array}$ & $\begin{array}{l}\mathrm{p}=40 \mathrm{~mm}, \\
\mathrm{AOA}=0^{\circ}\end{array}$ & $\begin{array}{l}\mathrm{p}=40 \mathrm{~mm}, \\
\mathrm{AOA}=15^{\circ}\end{array}$ & $\begin{array}{l}\mathrm{p}=40 \mathrm{~mm}, \\
\mathrm{AOA}=30^{\circ}\end{array}$ \\
\hline 5000 & 2.6 & 2.41 & 2.29 & 2.25 & 2.31 & 2.74 & 2.31 & 2.24 & 2.23 \\
\hline 15000 & 2.62 & 2.15 & 2.37 & 2.17 & 3.54 & 3.25 & 2.24 & 2.07 & 1.68 \\
\hline 25000 & 2.82 & 2.73 & 2.63 & 2.35 & 2.25 & 2.77 & 2.29 & 2.26 & 2.77 \\
\hline
\end{tabular}

Table 5 Ratio of $\mathbf{f f}_{\mathrm{AR}} / \mathbf{f f}_{\text {smooth }}$ for single step rib for different Reynolds number

\begin{tabular}{|c|c|c|c|c|c|c|c|c|c|}
\hline $\mathbf{R e}$ & 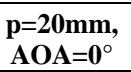 & $\begin{array}{l}\mathrm{p}=20 \mathrm{~mm}, \\
\text { AOA }=15^{\circ}\end{array}$ & $\begin{array}{l}\mathrm{p}=20 \mathrm{~mm}, \\
\mathrm{AOA}=30^{\circ}\end{array}$ & $\begin{array}{l}\mathrm{p}=30 \mathrm{~mm}, \\
\mathrm{AOA}^{\circ} 0^{\circ}\end{array}$ & $\begin{array}{l}\mathrm{p}=30 \mathrm{~mm}, \\
\text { AOA }=15^{\circ}\end{array}$ & $\begin{array}{l}\mathrm{p}=30 \mathrm{~mm}, \\
\mathrm{AOA}=30^{\circ}\end{array}$ & $\begin{array}{l}\mathrm{p}=40 \mathrm{~mm}, \\
\mathrm{AOA}=0^{\circ}\end{array}$ & $\begin{array}{l}\mathrm{p}=40 \mathrm{~mm}, \\
\mathrm{AOA}=15^{\circ}\end{array}$ & $\begin{array}{l}\mathrm{p}=40 \mathrm{~mm}, \\
\mathrm{AOA}=30^{\circ}\end{array}$ \\
\hline 5000 & 1.68 & 1.65 & 1.57 & 1.57 & 1.53 & 1.63 & 1.48 & 1.47 & 1.44 \\
\hline 15000 & 1.51 & 1.5 & 1.34 & 1.4 & 1.8 & 1.4 & 1.3 & 1.28 & 1.3 \\
\hline 25000 & 1.76 & 1.78 & 1.54 & 1.63 & 1.36 & 1.45 & 1.5 & 1.48 & 1.18 \\
\hline
\end{tabular}

\section{REFERENCES}

[1] Economic Survey, Volume-2 (2015-16), Ministry of Finance, Government of India https://www.thehindu.com/multimedia/archive/02752/Econ omic_Survey_-__2752570a.pdf

[2] Annual Report (2018-19), Central Electricity Authority, Ministry of Power, Government of India.http://cea.nic.in/reports/annual/annualreports/annual_r eport-2019.pdf

[3] Yadav, A. S., \& Bhagoria, J. L. (2014). A numerical investigation of square sectioned transverse rib roughened solar air heater. International Journal of Thermal Sciences, 79, 111-131. doi:10.1016/j.ijthermalsci.2014.01.008

[4] Maheshwari, B. K., Karwa, R., Singhvi, R., Goyal, A., Kumawat, R. N., Sharma, A. \& Bhardwaj, N. (2012). Performance study of solar air heater with baffled duct. J. Mech. Civil Eng, 4(5), 52-56.

[5] Thakur, D. S., Khan, M. K., \& Pathak, M. (2017). Performance evaluation of solar air heater with novel hyperbolic rib geometry. Renewable Energy, 105, 786-797. doi:10.1016/j.renene.2016.12.092
[6] Singh, A., \& Singh, S. (2017). CFD investigation on roughness pitch variation in non-uniform cross-section transverse rib roughness on Nusselt number and friction factor characteristics of solar air heater duct. Energy, 128 , 109-127. doi:10.1016/j.energy.2017.04.008

[7] Singh, S., Singh, B., Hans, V. S., \& Gill, R. S. (2015). CFD (computational fluid dynamics) investigation on Nusselt number and friction factor of solar air heater duct roughened with non-uniform cross-section transverse rib. Energy, 84, 509-517. doi:10.1016/j.energy.2015.03.015

[8] Singh, S., Chander, S., \& Saini, J. S. (2011). Heat transfer and friction factor correlations of solar air heater ducts artificially roughened with discrete V-down ribs. Energy, 36(8), 5053-5064. doi:10.1016/j.energy.2011.05.052

[9] Pandey, N. K., Bajpai, V. K., \& Varun. (2016). Experimental investigation of heat transfer augmentation using multiple arcs with gap on absorber plate of solar air heater. Solar Energy, 134, 314-326. doi:10.1016/j.solener.2016.05.007

[10] Kumar, T. S., Thakur, N. S., Kumar, A., \& Mittal, V. (2010). Use of artificial roughness to enhance heat transfer in solar air heaters-a review. Journal of Energy in Southern Africa, 21(1), 35-5 
[11] Sharma S. K., Nayyar A, Kumar C (2019). Heat Transfer Analysis of A Circular Tubes Using Extended Surfaces. An International Journal of Engineering, Science, Humanities and Management, SKIT Research Journal, 9(1), 86-92.

\section{NOMENCLATURE}

\begin{tabular}{|c|c|}
\hline CFD & Computational Fluid Dynamics \\
\hline D-B & Dittus-Boelter correlation \\
\hline $\mathbf{N u}$ & Nusselt Number \\
\hline $\mathbf{R e}$ & Reynolds Number \\
\hline SAH & Solar air heater \\
\hline $\begin{array}{l}\text { ASHRA } \\
\text { E }\end{array}$ & $\begin{array}{l}\text { American Society of Heating, Refrigerating, and } \\
\text { Air-Conditioning Engineers }\end{array}$ \\
\hline GIT & Grid independence Test \\
\hline $\mathbf{e}$ & Height of roughness \\
\hline $\mathbf{p}$ & Pitch of the roughness \\
\hline AOA & Angle of attack \\
\hline$q$ & Heat flux \\
\hline $\mathbf{A R}$ & Artificial Roughness \\
\hline $\mathbf{P}$ & Perimeter of duct \\
\hline$\eta$ & Thermo hydraulic performance parameter \\
\hline ff & Friction Factor \\
\hline
\end{tabular}

